\title{
Factors associated with self-reported capacity to walk, jog and run in individuals with systemic lupus erythematosus
}

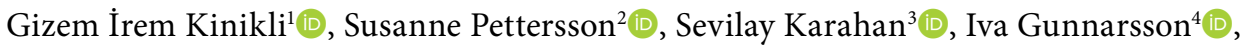 \\ Elisabet Svenungsson ${ }^{4} \mathbb{D}$, Carina Boström ${ }^{5}$ D \\ ${ }^{1}$ Department of Orthopedic Physiotherapy and Rehabilitation, Hacettepe University, Faculty of Physical Therapy and Rehabilitation, Ankara, Turkey \\ ${ }^{2}$ Karolinska University Hospital, Theme Inflammation and Infection, Po Gastro Hud Och Reuma, Stockholm, Sweden \\ ${ }^{3}$ Department of Biostatistics, Hacettepe University Faculty of Medicine, Ankara, Turkey \\ ${ }^{4}$ Department of Medicine, Division of Rheumatology, Karolinska Institute, Stockholm, Sweden \\ ${ }^{5}$ Department of Neurobiology, Care Sciences and Society, Karolinska Institute, Stockholm, Sweden
}

\begin{abstract}
Objectives: This study aims to explore how disease and health-related quality of life (HRQOL) factors are associated with self-reported physical capacity in walking, jogging and running in systemic lupus erythematosus (SLE).

Patients and methods: This cross-sectional study is part of an ongoing cohort research project which started in 2014 . A total of 198 patients (21 males, 177 females; mean age: $51.5 \pm 16.1$ years; range, 20 to 82 years) with SLE answered a question concerning physical capacity and the answers were categorized as low (can walk less than $2 \mathrm{~km}$ ) and high (can jog and run at least $2 \mathrm{~km}$ ) capacity. Additional measurements of disease activity (Systemic Lupus Activity Measure-Revised, SLAM-R), organ damage (Systemic Lupus International Collaborating Clinics-Damage Index, SLICC-DI), physical activity (International Physical Activity Questionnaire-Short Form, IPAQ-SF), exercise during the past year, Hospital Anxiety and Depression Scale (HADS), and HRQOL according to EuroQol five-dimension score and EuroQol visual analog scale (EQ-VAS) were included. The independent variables in the multiple logistic regression analysis were age, body mass index (BMI), disease duration, SLAM-R, SLICC-DI, IPAQ-SF category, sitting hours (IPAQ-SF), and exercise during the past year as well as HADS and EQ-VAS.

Results: Patients that reported low physical capacity $(n=120)$ were older $(p<0.001)$, had longer disease duration $(p<0.001)$, had more organ damage $(p<0.001)$, reported that they were less physically active $(p=0.003)$, exercised less during the past year $(p=0.001)$, reported more pain/discomfort and depressive symptom $(p<0.001)$ and had lower overall HRQOL $(p<0.001)$ and mobility and usual activities than those that reported high capacity $(n=78)$. The regression analysis showed that age (median $\leq 49$ vs $>49$ ) (Exp) (B): 4.52 (95\% confidence interval [Cl]: 2.05 to 9.98$)(p<0.001)$, disease duration (median $\leq 17$ vs >17) $\operatorname{Exp}(\mathrm{B}): 2.53$ (95\% Cl: 1.15 to 5.60) ( $p=0.02$ ), SLICC-DI (median <1 vs $\geq 1$ ) Exp (B): 3.60 (95\% Cl: 1.48 to 8.73 ) ( $p=0.005)$, and EQ-VAS (median <72 vs $\geq 72)$ Exp (B): $4.63(95 \% \mathrm{Cl}: 2.13$ to 10.05$)(p<0.001)$ were significant factors associated with physical capacity (Nagelkerke $R$ Squared=0.46).

Conclusion: Patients with low physical capacity were less physically active, exercised less and had more pain and depressive symptoms than those that reported a high capacity. However, only age, disease duration, organ damage and overall HRQOL were indicators of low physical capacity. In order to increase physical capacity in the management of SLE, it is important to address overall HRQOL.

Keywords: Health perceptions, health-related quality of life, physical activity, physical capacity, systemic lupus erythematosus, depressive symptoms.
\end{abstract}

Systemic lupus erythematosus (SLE) is a chronic inflammatory and autoimmune disease that affects mainly females and is associated with exacerbations and remissions within a broad clinical spectrum ranging from very mild forms to major organ involvement that can cause significant morbidity and mortality. Many tissues are targeted by the disease including

\section{Received: May 03, 2020 Accepted: July 03, 2019 Published online: December 10, 2020}

Correspondence: Gizem İrem Kınıklı, PhD., PT. Hacettepe Üniversitesi Fizik Tedavi ve Rehabilitasyon Fakültesi, Ortopedik Fizyoterapi ve Rehabilitasyon Bölümü, 06100 Samanpazarı, Ankara, Türkiye.

Tel: +90 312 - 3052525 / 208 e-mail: cguvendik@hotmail.com

Kinikli Gl, Pettersson S, Karahan S, Gunnarsson I, Svenungsson E, Boström C. Factors associated with self-reported capacity to walk, jog and run in individuals with systemic lupus erythematosus. Arch Rheumatol 2021;36(1):89-100.

This is an open access article under the terms of the Creative Commons Attribution-NonCommercial License, which permits use, distribution and reproduction in any medium, provided the original work is properly cited and is not used for commercial purposes (http://creativecommons.org/licenses/by-nc/4.0/). 
the skin, joints, kidneys, brain nerves, heart, blood vessels and lungs. ${ }^{1}$ Individuals with SLE also have a markedly increased risk incidence of cardiovascular diseases. ${ }^{2}$

Both the physical and mental health-related quality of life (HRQOL) is reduced in patients with SLE in comparison to the healthy general population and many patients experience anxiety and depression. ${ }^{3}$ Furthermore, musculoskeletal manifestations are common in SLE. Exercise capacity and the level of physical activity and exercise are reduced, also reflected by the fact that individuals with SLE report lower physical capacity such as walking, jogging and running than the general population..$^{2,4-11}$ Reduced exercise capacity is associated with higher rates of mortality in the general population. ${ }^{6}$ Poor self-reported physical function is an independent predictor of mortality in SLE, even after adjusting for disease duration, disease activity and damage, ${ }^{5}$ indicating that physical function is of importance to measure when monitoring patients with SLE.

Lack of physical activity and sedentary behavior have been identified as risk factors for cardiovascular disease in the general population ${ }^{12}$ and similar associations have also been presented in SLE. ${ }^{7}$ A higher amount of physical activity and exercise are associated with accelerated atherosclerosis and increased cardiovascular morbidity and mortality in SLE. ${ }^{13}$ From systematic reviews, meta-analysis and EULAR recommendations, we know that physical exercise in SLE with inactive/mild or moderate disease activity and no or low organ damage increase aerobic capacity, reduce fatigue and depressive symptoms without increasing disease activity and organ damage. ${ }^{9,14}$

Both disease-related factors such as lower-limb strength, self-reported general health and pain, and as well as age are independent predictors of six-minute walk test (6MWT) performance in older people $e^{15,16}$ and in patients with knee osteoarthritis. ${ }^{17}$ In patients with systemic sclerosis many factors have been reported as associated to 6MWT. ${ }^{18}$ In SLE, aspects of HRQOL such as physical functioning, social functioning, emotional well-being and the mental component according to short form-36 health survey subscales are indicators of the results of the 6MWT. ${ }^{10}$ Whether aspects of HRQOL and depressive symptoms can influence how patients experience their physical capacity is less studied. In this study, we aimed to explore how disease and HRQOL factors are associated with self-reported physical capacity in walking, jogging and running in SLE.

\section{PATIENTS AND METHODS}

This cross-sectional study is part of an ongoing cohort research project at Karolinska University Hospital, Sweden which started in $2014 .{ }^{19}$ All participants were $\geq 18$ years of age and met at least four of the American College of Rheumatology (ACR) 1982 revised criteria for SLE. ${ }^{20}$ Exclusion criteria were not being able to read, understand and/or sign the informed consent in Swedish. A rheumatologist performed physical examination and assessed disease activity and disease-specific manifestations. Disease duration was set according to the revised ACR criteria for the classification of SLE. ${ }^{20}$ The study protocol was approved by the regional ethical review board of Karolinska University Hospital (2014/1337-31/2). A written informed consent was obtained from each patient. The study was conducted in accordance with the principles of the Declaration of Helsinki.

We used the Systemic Lupus Activity MeasureRevised (SLAM-R) to assess disease activity. It includes 32 items, divided into 11 organ systems (malar rash, discoid rash, photosensitivity, oral ulcer, arthritis, serositis, renal disorder, neurological disorder, hematological disorder, immunological disorder, anti-nuclear antibody) and estimates a degree of severity for the last month. The score range is $0-86$, where a score $\geq 7$ is considered as a flare. ${ }^{21}$ Furthermore, we used the Systemic Lupus International Collaborating Clinics (SLICC)/ACR-Damage Index (DI) to assess cumulative organ damage. It includes 12 items (ocular, neuropsychiatric, renal, pulmonary, cardiovascular, peripheral vascular, gastrointestinal, musculoskeletal, skin, premature gonadal failure, diabetes, malignancy) divided into nine organ systems with scores ranging from 0 to $47 .{ }^{22}$ SLICC-DI captures manifestations persisting continuously for at least six months after the onset of SLE as damage. A SLICC/ACR-DI score $\geq 1$ was considered as organ damage. 
The included SLE patients were asked to complete the self-reported questions/ questionnaires described below:

Physical capacity was assessed with the question "How much do you think you can manage (walk, jog or run)?" from the Physical Activity Questionnaire (PAQ) utilized in this study. PAQ was inspired from a larger questionnaire which used to describe the physical capacity and activity in epidemiological studies of the Swedish general population. ${ }^{23}$ The answer alternatives of the question are: (i): I cannot walk without help or handicap aids; (ii): I can move about indoors; (iii): I can walk $100 \mathrm{~m}$ without resting; (iv): I can walk $500 \mathrm{~m}$ without resting; (v): I can walk $1 \mathrm{~km}$ without resting; (vi): I can walk $2 \mathrm{~km}$ without resting; (vii): I can jog $2 \mathrm{~km}$ if I can rest a few times; (viii): I can jog $2 \mathrm{~km}$ without resting; (ix): I can run $2 \mathrm{~km}$ at a reasonable speed if I can rest a few times; (x): I can run $2 \mathrm{~km}$ at a reasonable speed without resting; (xi): I can run $2 \mathrm{~km}$ at a high speed without resting.

Physical exercise during the past year was assessed with the following question from PAQ: "How much did you exercise in average during the past year?": (i): I never exercise; (ii): I exercise irregularly; (iii): I exercise about once a week; (iv): I exercise twice a week; (v): I exercise three times a week or more.

The questions about physical capacity and exercise during the past year from PAQ have "satisfactory" content validity and moderate-good test-retest reliability in patients with SLE. ${ }^{4}$

Physical activity and sitting hours last week were assessed with International Physical Activity Questionnaire Short-Form (IPAQ-SF) (8-items), which provides information on total physical activity in metabolic equivalent tasks (MET)-minutes/week and time spent sitting (sitting hours per day). ${ }^{24}$ The intensity of an activity is computed by weighting each type of activity by its energy requirements defined in METs and multiplying the MET score by the time (in minutes) the activity was performed for (walking 3.3, moderate physical activity 4.0, and vigorous physical activity 8.0). The IPAQ-SF also classifies populations into the following categories: inactive (scores of <599), minimally active (scores between 600 and 2,999) or health enhancing physical activity (HEPA) level (scores over 3,000) groups. A Swedish validated version of the IPAQ-SF was used in this study. ${ }^{25}$

The Hospital Anxiety and Depression Scale (HADS) was used to assess symptoms of anxiety and depression divided equally into two scales; an anxiety and depression scale (HADS-D) each consisting of seven items (total 14 questions) based on feelings during the past week. The range for each scale is 0-21. Bjelland et al. ${ }^{26,27}$ identified a cut-off point of $8 / 21$ for anxiety or depression. Scores between 8 and 10 indicate borderline, whilst scores equal to or higher than 11 both in the anxiety and depression subscales represent a clinically significant state of anxiety or depression. The HADS in English is valid for people with SLE. ${ }^{26}$ We used a Swedish translation of the HADS that has been evaluated for psychometric aspects. ${ }^{26,27}$

The EuroQol five-dimension three level scale (EQ-5D-3L) was used to assess HRQOL and health state. It consists of a descriptive system and the EQ visual analog scale (EQ-VAS). ${ }^{28}$ The EQ-5D-3L descriptive system consists of five dimensions: mobility, self-care, usual activities, pain/discomfort and anxiety/depression of which each can take one of three responses: "no problems, some problems, and extreme problems". The EQ-VAS score is recorded to indicate EQ-5D health state where "0" corresponded to the worst imaginable health and "100" corresponded to the best imaginable health. The EQ-5D-3L has satisfactory psychometric properties in patients with SLE. ${ }^{29}$ We used a Swedish translation of EQ-5D-3L. ${ }^{30}$

\section{Statistical analysis}

All data were mostly nominal and ordinal, therefore, medians with interquartile ranges (IQRs) and percentages are presented (Table 1, 2). The Pearson's chi-squared test was used for comparative analysis. When the Pearson's chisquared test was not appropriate, the likelihood ratio test was used to determine whether there was a significant association between categorical variables in Table 3. For sample size calculation for the regression analysis, setting a significance level of equal to $0.05(\alpha)$ and power at $80 \%(1-\beta)$, an expected odds ratio (OR) of 2 were estimated on 184 subjects for self-reported physical capacity variable. ${ }^{31} \mathrm{G}^{*}$ Power 3.1.9.4 (Heinrich-HeineUniversität Düsseldorf, Düsseldorf, Germany) was used for sample size calculation. 


\begin{tabular}{|c|c|c|c|c|}
\hline Variables & $\mathrm{n}$ & $\%$ & Median & $\mathrm{Q}_{1}-\mathrm{Q}_{3}$ \\
\hline Age (year) & 198 & & 49.5 & $40-66$ \\
\hline Body mass index $\left(\mathrm{kg} / \mathrm{m}^{2}\right)$ & 198 & & 23.8 & $21.4-23.8$ \\
\hline Disease duration (year) & 194 & & 17 & $6-33$ \\
\hline SLAM-R (0-86 points) & 186 & & 6 & 3-9.3 \\
\hline SLICC/ACR-DI (0-47 points) & 185 & & 1 & $0-2$ \\
\hline HADS-depression (0-21 points) & 187 & & 4 & $2-7$ \\
\hline HADS-anxiety (0-21 points) & 188 & & 6 & $3-8$ \\
\hline EQ-VAS (0-100 mm) & 188 & & 72.2 & 22.1 \\
\hline $\begin{array}{l}\text { EQ-5D* Mobility (1-3 points) } \\
1 \\
2 \\
3\end{array}$ & 180 & $\begin{array}{c}65.7 \\
24.7 \\
0.5\end{array}$ & & \\
\hline $\begin{array}{l}\text { EQ-5D* Selfcare (1-3 points) } \\
\quad 1 \\
2 \\
3\end{array}$ & 180 & $\begin{array}{c}84.8 \\
6.1 \\
0\end{array}$ & & \\
\hline $\begin{array}{l}\text { EQ-5D* Usual activities (1-3 points) } \\
1 \\
2 \\
3\end{array}$ & 180 & $\begin{array}{c}65.7 \\
22.2 \\
3.0\end{array}$ & & \\
\hline $\begin{array}{l}\text { EQ-5D* Pain/discomfort (1-3 points) } \\
\qquad \begin{array}{l}1 \\
2 \\
3\end{array}\end{array}$ & 180 & $\begin{array}{c}23.7 \\
62.1 \\
5.1\end{array}$ & & \\
\hline $\begin{array}{l}\text { EQ-5D* Anxiety/depression (1-3 points) } \\
1 \\
2 \\
3\end{array}$ & 180 & $\begin{array}{c}30.8 \\
56.1 \\
4\end{array}$ & & \\
\hline
\end{tabular}

For the statistical analysis, the answer alternatives in the question concerning physical capacity for walking, jogging and running were categorized as "low" ( $=120)$ and "high" physical capacity $(\mathrm{n}=78)$ (dummy variables) from the median: answer alternative 6 (IQR: 2), respectively, according to the following alternatives: $0=1-6$ (low) and 1=7-11 (high) (Table 3). For the logistic regression analysis, all independent variables were dichotomized according to their median as the dependent variable (physical capacity) was also dichotomized. ${ }^{31}$ For the exercise during the past year question, the following dummy variables were developed from the median value of categories which was according to answer alternatives: 0=1-2 (never-irregular) and 1=3-5 (once, twice, three times/week) (Table 3). Variables [age, body mass index (BMI), disease duration, SLICC-DI, HADS-D, EQ-VAS, all EQ-5D subscales except anxiety and depression, IPAQ-SF category, sitting hours (IPAQ-SF) and physical exercise past year] that had values less than $\mathrm{p}<0.20$ according to Pearson's chi-squared test were chosen as the independent variables in the multiple logistic regression analysis to determine factors associated to physical capacity with a stepwise elimination procedure (Table 4). ${ }^{31}$ The results of the regression model were expressed in terms of ORs and 95\% confidence intervals (95\% CIs) (Table 5). The goodness of fit of the final model was assessed by the Hosmer and Lemeshow test. ${ }^{31}$ The significance level of a $p$ value was considered significant if $\mathrm{p} \leq 0.05$. The IBM SPSS version 23 software (IBM Corp., Armonk, NY, USA) was used for statistical analysis. 


\begin{tabular}{|c|c|c|c|c|}
\hline Variables & $\mathrm{n}$ & $\%$ & Median & $\mathrm{Q}_{1}-\mathrm{Q}_{3}$ \\
\hline Total IPAQ-SF (MET-min/week) & 183 & & 1188 & $495-2772$ \\
\hline Sitting hours per day (IPAQ-SF) (h) & 198 & & 5 & $3-8$ \\
\hline $\begin{array}{l}\text { How much do you think you can manage } \\
\text { concerning walk, jog, and run? }\end{array}$ & 198 & & & \\
\hline $\begin{array}{l}\text { Low physical capacity (answer alternatives 1-6) } \\
\text { 1: Cannot walk without help } \\
\text { 2: Can move about indoors } \\
\text { 3: Can walk } 100 \mathrm{~m} \\
\text { 4: Can walk } 500 \mathrm{~m} \\
\text { 5: Can walk } 1 \mathrm{~km} \\
\text { 6: Can walk } 2 \mathrm{~km}\end{array}$ & & $\begin{array}{c}4.5 \\
3.5 \\
2.5 \\
3 \\
7.1 \\
53\end{array}$ & & \\
\hline $\begin{array}{l}\text { High physical capacity (answer alternatives 7-11) } \\
\text { 7: Can jog } 2 \mathrm{~km} \text { if resting } \\
\text { 8: Can jog } 2 \mathrm{~km} \\
\text { 9: Can run } 2 \mathrm{~km} \text { at a reasonable speed if resting } \\
\text { 10: Can run } 2 \mathrm{~km} \text { at a reasonable speed } \\
\text { 11: Can run } 2 \mathrm{~km} \text { at a high speed }\end{array}$ & & $\begin{array}{c}7.6 \\
7.6 \\
3 \\
5.1 \\
3\end{array}$ & & \\
\hline $\begin{array}{l}\text { Exercise past year } \\
\text { 1: Never exercise } \\
\text { 2: Exercise irregularly } \\
\text { 3: Exercise once/week } \\
\text { 4: Exercise twice/week } \\
\text { 5: Exercise three times/week or more }\end{array}$ & 151 & $\begin{array}{c}16.7 \\
46.5 \\
7.6 \\
11.6 \\
17.6\end{array}$ & & \\
\hline
\end{tabular}

\section{RESULTS}

The demographic characteristics of study participants are shown in Table 1. Individuals with SLE and low organ damage were included. Overall disease activity was also low, with 107 (54\%) patients in remission $(<7$ in SLAM-R), and 91 $(46 \%)$ patients in flare with a score $\geq 7 .{ }^{4}$ The majority of the patients had moderate problems with pain/discomfort and anxiety/depression according to EQ-5D-3L. Anxiety and depressive symptoms according to HADs were in median low (Table 1).

Fifty-three percent of the patients estimated that they can walk $2 \mathrm{~km}$ without resting and $46.5 \%$ reported that they exercised irregularly during the past year. Considering IPAQ-SF category, we found that 67 individuals (33.8\%) were physically inactive (scores of $<599$ ), 87 (43.9\%) individuals were minimally active (scores between 600 and 2,999), and 44 (22.2\%) individuals were in the HEPA level (scores over 3,000) of physical activity. Descriptive characteristics of physical capacity, physical activity and exercise in individuals of SLE were demonstrated in Table 2.

Patients that reported low physical capacity to walk, jog and run $(n=120)$ were older $(p<0.001)$ with longer disease duration $(p<0.001)$ and more organ damage $(p<0.001)$, were less physically active according to IPAQ-SF $(p=0.003)$ and reported that they exercised less during the past year $(p=0.001)$, had lower overall HRQOL according to EQ-5D VAS $(p<0.001)$ and lower mobility and usual activities (EQ-5D) while having more pain/discomfort $(E Q-5 D) \quad(p<0.001)$ and depressive symptoms according to HADS-D $(p<0.001)$ than those with high physical capacity (Table 3).

According to Pearson's chi-squared test, age $(p<0.001)$, body mass index $(p=0.07)$, disease duration $(p<0.001)$, organ damage $(p<0.001)$, IPAQ-SF category $(p=0.05)$, sitting hours per day (IPAQ-SF) $(p=0.11)$, exercise during the past year $(p=0.004)$, EQ-VAS $(p<0.001)$ and HADS-D $(p=0.04)$ as well as the subscales in the EQ-5D dimensions (mobility $[p<0.001]$, 
Table 3. Comparison of independent variables between patients with low and high physical capacity

\begin{tabular}{|c|c|c|c|c|c|c|c|c|c|}
\hline \multirow[b]{2}{*}{ Variables } & \multicolumn{4}{|c|}{ Low physical capacity $(\mathrm{n}=120)$} & \multicolumn{4}{|c|}{ High physical capacity $(\mathrm{n}=78)$} & \multirow[b]{2}{*}{$p$} \\
\hline & $\%$ & Mean \pm SD & Median & $\mathrm{Q}_{1}-\mathrm{Q}_{3}$ & $\%$ & Mean \pm SD & Median & $\mathrm{Q}_{1}-\mathrm{Q}_{3}$ & \\
\hline Age (year) & & $57.8 \pm 15.3$ & & & & $41.9 \pm 12.1$ & & & $<0.001$ \\
\hline Body mass index $\left(\mathrm{kg} / \mathrm{m}^{2}\right)$ & & $24.9 \pm 4.8$ & & & & $24.5 \pm 4.5$ & & & 0.34 \\
\hline Disease duration (year) & & & 26 & $13-37$ & & & 11 & $5-21$ & $<0.001$ \\
\hline SLAM-R (0-86 points) & & & 6 & $3.1-9.0$ & & & 6 & $3-9$ & 0.53 \\
\hline SLICC/ACR-DI (0-47 points) & & & 1 & $0-4$ & & & 0 & $0-0$ & $<0.001$ \\
\hline Total IPAQ-SF (MET-min/week) & & & 952.5 & $396-2453.2$ & & & 1516 & 773-3132 & 0.003 \\
\hline Sitting hours per day (IPAQ-SF) (h) & & & 4 & $2.25-8$ & & & 6 & $3-8$ & 0.18 \\
\hline $\begin{array}{l}\text { Exercise past year (\%) } \\
\text { 1: Never exercise } \\
\text { 2: Exercise irregularly } \\
\text { 3: Exercise once/week } \\
\text { 4: Exercise twice/week } \\
\text { 5: Exercise three times/week or more }\end{array}$ & $\begin{array}{c}25.8 \\
41.7 \\
5.8 \\
9.2 \\
17.5\end{array}$ & & & & $\begin{array}{c}2.6 \\
53.8 \\
10.3 \\
15.4 \\
17.9\end{array}$ & & & & 0.001 \\
\hline HADS-Depression (0-21) & & & 5 & $3-8$ & & & 3 & $1-6$ & 0.001 \\
\hline HADS-Anxiety (0-21) & & & 6 & $3-8$ & & & 6 & $2.5-9$ & 0.45 \\
\hline EQ-VAS (mm) & & & 65 & $49-72.5$ & & & 72.5 & $54.2-89.5$ & $<0.001$ \\
\hline EQ-5D* Mobility (1-3) & & & 1 & $1-2$ & & & 1 & $1-1$ & $<0.001$ \\
\hline EQ-5D* Selfcare (1-3) & & & 1 & $1-1$ & & & 1 & $1-1$ & 0.09 \\
\hline EQ-5D* Usual activities (1-3) & & & 1 & $1-2$ & & & 1 & $1-1$ & $<0.001$ \\
\hline EQ-5D* Pain/discomfort (1-3) & & & 2 & $2-2$ & & & 2 & $1-2$ & $<0.001$ \\
\hline EQ-5D* Anxiety/depression (1-3) & & & 2 & $1-2$ & & & 2 & $1-2$ & 0.31 \\
\hline
\end{tabular}

self-care [p=0.127], usual activities $[p<0.001]$, pain/discomfort $[p<0.001])$ were significantly associated with physical capacity with a $\mathrm{p}$ value of $<0.20$ (Table 4). Sex $(p=0.92)$, disease activity $($ SLAM-R) $(p=0.74)$ and EQ-5D anxiety/depression $(\mathrm{p}=0.515)$ were not associated with physical capacity (Table 4).

The regression analysis showed that the factors associated with low physical capacity in multiple logistic regression analysis were age (median $\leq 49$ vs >49) (Еxp) (B): 4.52 (95\% confidence interval $[\mathrm{CI}]: 2.05$ to 9.98$)(\mathrm{p}<0.001)$, disease duration (median $\leq 17$ vs >17) $\operatorname{Exp}$ (B): 2.53 (95\% CI: 1.15 to 5.60$)(p=0.02)$, SLICC-DI (median $<1$ vs $\geq 1$ ) $\operatorname{Exp}$ (B): 3.60 (95\% CI: 1.48 to 8.73 ) $(\mathrm{p}=0.005)$, and EQ-VAS (median $<72$ vs $\geq 72$ ) Exp (B): 4.63 (95\% CI: 2.13 to 10.05$)(p<0.001)$ (Nagelkerke R Squared=0.46) (Table 5).

The OR for low physical capacity was 4.52-fold higher in individuals older than 49 years compared to those who were younger. The OR for low physical capacity was 2.53-fold higher in individuals with disease duration longer than 17 years according to median value. The $\mathrm{OR}$ for low physical capacity was 3.60-fold higher in individuals with more than 1 point in the SLICC-DI compared to those that had less than 1 point. The EQ-VAS scores were inversely associated with physical capacity $(p<0.001$; Exp (B): 4.63). Individuals with $\mathrm{EQ}$-VAS scores $<72 \mathrm{~mm}$ were 4.62 times more likely to be at increased risk of low physical capacity than those who reported higher EQ-VAS scores ( $\geq 72$ ) (Table 5).

\section{DISCUSSION}

The aim of this study was to explore how disease- and HRQOL-related factors are associated with self-reported physical capacity in walking, jogging and running in individuals with SLE. Patients who reported low physical capacity were older, had longer disease duration, more organ damage, and reported less overall HRQOL, less mobility and usual activities, more pain 
Table 4. Associations between physical capacity (How much do you think you can manage concerning walk, jog and run?) and independent dichotomous variables according to median ( $n=198)$

\begin{tabular}{|c|c|c|c|c|c|}
\hline \multirow[b]{2}{*}{ Dichotomous variables } & \multicolumn{2}{|c|}{$\begin{array}{l}\text { Low physical capacity } \\
\text { (answer alternatives 1-6) }\end{array}$} & \multicolumn{2}{|c|}{$\begin{array}{l}\text { High physical capacity } \\
\text { (answer alternatives 7-11) }\end{array}$} & \multirow[b]{2}{*}{$p$} \\
\hline & $\mathrm{n}$ & $\%$ & $\mathrm{n}$ & $\%$ & \\
\hline \multicolumn{5}{|l|}{ Age (year) } & \multirow[t]{3}{*}{$<0.001$} \\
\hline$\leq 49$ & 37 & 30.8 & 62 & 79.5 & \\
\hline$>49$ & 83 & 69.2 & 16 & 20.5 & \\
\hline \multicolumn{5}{|l|}{ Sex } & \multirow[t]{3}{*}{0.92} \\
\hline Female & 108 & 90 & 69 & 88.5 & \\
\hline Male & 12 & 10 & 9 & 11.5 & \\
\hline \multicolumn{5}{|l|}{ Body mass index $\left(\mathrm{kg} / \mathrm{m}^{2}\right)$} & \multirow[t]{3}{*}{0.07} \\
\hline$\leq 23.8$ & 52 & 43.3 & 44 & 56.4 & \\
\hline$>23.8$ & 68 & 56.7 & 34 & 43.6 & \\
\hline \multicolumn{5}{|l|}{ Disease duration (year) } & \multirow[t]{3}{*}{$<0.001$} \\
\hline$\leq 17$ & 45 & 37.5 & 58 & 74.4 & \\
\hline & 75 & 62.5 & 20 & 25.6 & \\
\hline & \multirow[t]{3}{*}{0.74} \\
\hline$<7$ : Remission & 66 & 55 & 41 & 52.6 & \\
\hline$\geq 7:$ Flare & 54 & 45 & 37 & 47.4 & \\
\hline \multicolumn{5}{|l|}{ SLICC/ACR-DI (0-47 points) } & \multirow[t]{3}{*}{$<0.001$} \\
\hline$<1$ & 53 & 48.2 & 66 & 88 & \\
\hline & 57 & 51.8 & 9 & 12 & \\
\hline \multicolumn{5}{|l|}{ IPAQ category (1-3) } & \multirow[t]{4}{*}{0.05} \\
\hline 1: scores of $<599$ & 48 & 40 & 19 & 24.4 & \\
\hline 2: scores between 600 and 2,999 & 50 & 41.7 & 37 & 47.4 & \\
\hline 3: scores over 3,000 & 22 & 18.3 & 22 & 28.2 & \\
\hline Sitting hours per day (IPAQ-SF) & & & & & 0.11 \\
\hline $0=4 \mathrm{~h}$ & 74 & 61.7 & 39 & 50 & \\
\hline $1=6 \mathrm{~h}$ & 46 & 38.3 & 39 & 50 & \\
\hline Exercise past year & & & & & 0.004 \\
\hline 1-2: (never - irregular) & 60 & 60.6 & 18 & 34.6 & \\
\hline $3,4,5:$ (once, twice, three times) & 39 & 36.4 & 34 & 65.4 & \\
\hline EQ-VAS (mm) & & & & & $<0.001$ \\
\hline$<72$ & 79 & 71.2 & 34 & 47.2 & \\
\hline$\geq 72$ & 32 & 28.8 & 38 & 52.8 & \\
\hline HADS-Depression (0-21 points) & & & & & 0.04 \\
\hline$<4$ & 57 & 47.5 & 49 & 62.8 & \\
\hline$\geq 4$ & 63 & 52.5 & 29 & 37.2 & \\
\hline EQ-5D mobility & & & & & $<0.001$ \\
\hline 1: No problems & 65 & 60.2 & 65 & 90.3 & \\
\hline 2: Some problems & 43 & 39.8 & 6 & 8.3 & \\
\hline 3: Extreme problems & - & & 1 & 1.4 & \\
\hline EQ-5D selfcare & & & & & 0.127 \\
\hline 1: No problems & 98 & 90.7 & 70 & 97.2 & \\
\hline 2: Some problems & 10 & 9.3 & 2 & 2.8 & \\
\hline 3: Extreme problems & - & - & - & - & \\
\hline EQ-5D usual activities & & & & & $<0.001$ \\
\hline 1: No problems & 67 & 62.0 & 63 & 87.5 & \\
\hline 2: Some problems & 37 & 34.3 & 7 & 9.7 & \\
\hline 3: Extreme problems & 4 & 3.7 & 2 & 2.8 & \\
\hline EQ-5D pain/discomfort & & & & & $<0.001$ \\
\hline 1: No problems & 17 & 15.7 & 30 & 41.7 & \\
\hline 2: Some problems & 82 & 75.9 & 41 & 56.9 & \\
\hline 3: Extreme problems & 9 & 8.3 & 1 & 1.4 & \\
\hline EQ-5D anxiety/depression & & & & & 0.515 \\
\hline 1: No problems & 34 & 31.5 & 27 & 37.5 & \\
\hline 2: Some problems & 68 & 63 & 43 & 59.7 & \\
\hline 3: Extreme problems & 6 & 5.6 & 2 & 2.8 & \\
\hline
\end{tabular}


Table 5. Associated factors of low self-reported physical capacity (How much do you think you can manage concerning walk, jog and run?) from multiple logistic regression analysis ( $n=198)$

\begin{tabular}{lccccc}
\hline Final model & Beta & SE of Beta & OR & $95 \%$ CI of OR & $p$ \\
\hline Age (median $\leq 49$ vs. $>49)$ & 1.51 & 0.40 & 4.52 & 2.05 to 9.98 & $<0.001$ \\
Disease duration (median $\leq 17$ vs. $>17$ ) & 0.93 & 0.41 & 2.53 & 1.15 to 5.60 & 0.022 \\
SLICC/ACR-DI (median $<1$ vs. $\geq 1$ ) & 1.28 & 0.45 & 3.60 & 1.48 to 8.73 & 0.005 \\
EQ-VAS (median $<72$ vs. $\geq 72$ ) & 1.53 & 0.40 & 4.63 & 2.13 to $10.05<$
\end{tabular}

SE: Standard error; OR: Odds ratio; CI: Confidence interval; SLICC/ACR-DI: Systemic Lupus International Collaborating Clinics/American College of Rheumatology Damage-Index; EQ-VAS: EuroQol five-dimension visual analog scale; Nagelkerke R Squared=0.461; Logistic regressions adjusted for age and sex is in final model.

and depressive symptoms (according to HADS). Patients with low physical capacity also reported that they were less physically active and exercised less than those who reported higher physical capacity. However, in the logistic regression analysis, only older age, longer disease duration, worse organ damage and worse overall HRQOL indicated worse physical capacity in this sample with in average inactive/mild disease activity and no to low organ damage. In order to increase physical capacity in the management of SLE, it is important to address overall HRQOL, while our results also indicate that pain and depressive symptoms are also important to deal with.

In our sample, there was an interaction between age and physical capacity, which was not surprising and is similar as in the general population and in other populations.,12,17,32 It is well known that early diagnosis and medical treatment together with younger age is associated with higher physical capacity in SLE. ${ }^{33}$ In our sample, longer disease duration and more organ damage were also indicators of low physical capacity. Similar results have been found in patients with ankylosing spondylitis (AS), where a specific subtype of the disease and worse physical function were associated with less physical activity at vigorous intensity. ${ }^{34}$ As longer disease duration is known to be correlated with an increased risk of organ damage and comorbidities in SLE, ${ }^{35}$ besides medical treatment, preventive strategies such as engaging in physical activity and exercise should be applied to minimize disease worsening. ${ }^{36}$

Careful monitoring of physical capacity is vital for patients at regular controls since decline in self-reported physical capacity could be a signal for their physical limitations and a risk for future mortality. ${ }^{1}$ Health professionals should also support elderly patients with SLE to increase their physical capacity and enable them to be physically active to minimize potential comorbidities.

Our study showed that the way patients experience their HRQOL or health state are associated with how they experience their physical capacity, which is in line with earlier studies in SLE showing that both physical and mental aspects of HRQOL were predictors of the 6MWT. ${ }^{37}$ Comparable results have also been presented in patients with AS, where higher HRQOL (EQ-5D) was associated with higher physical activity at vigorous intensity. ${ }^{34}$ Patients reporting low physical capacity in our study reported, besides less overall HRQOL, less mobility and usual activities, and more pain and depressive symptoms (HADS-D) than those with high capacity. Similarly, achievement of physical activity goals seems to be related to higher levels of quality of life and lower pain in patients with rheumatoid arthritis (RA). ${ }^{38}$ In order to increase physical capacity in patients with SLE, our study indicates that HRQOL, reflecting both physical and mental aspects of health, should be addressed in the management of SLE. Pain and depressive symptoms are important to follow as it might influence patient's ability to physical capacity. Besides musculoskeletal manifestations and cardiopulmonary involvement, fatigue, fibromyalgia and depression have been presented as barriers to physical activity in SLE. ${ }^{9,39}$ In our study, anxiety and depressive symptoms were not indicators of physical capacity comparable with the results from a study concerning AS, ${ }^{34}$ however others have found that depressive symptoms where one of the predictors of walking 
distance in older adults. ${ }^{16,40}$ One reason for the discrepancy might be that the majority of our patients were not so depressed. While $46 \%$ of the patients had anxiety according to the cut-off for HADS, $43 \%$ had mild to moderate depression. Nevertheless, the scores both for anxiety and depression was in median value higher than for the general population. ${ }^{41}$ According to EQ-5D, over 50\% reported "some problems" with depression and the median EQ-5D anxiety/depression scores were higher than the average of general population. ${ }^{41}$ Different questionnaires might capture different aspects of depressive symptoms. ${ }^{41,42}$

We did not find any association between disease activity and physical capacity. There are no conclusive results on whether disease activity is associated with physical capacity in SLE. ${ }^{43-45}$ Many similar studies report low disease activity in SLE, but disease activity fluctuates through disease process and it is possible that patients with high disease activity are underrepresented in cross-sectional studies like this one. ${ }^{46,47}$ Surprisingly, IPAQ-SF total score (METs-min/week), exercise during the past year and sitting behavior were not indicators of self-reported physical capacity in our regression analysis. However, patients that reported low physical capacity were less physically active according to IPAQ and exercised less the last year.

Self-reported physical capacity is a strong predictor of who will engage in physical activity. ${ }^{48}$ Low self-reported capacity to perform physical activity was strongly and independently associated with cardiovascular events and superior to self-assessed physical activity in predicting cardiovascular events in middle-aged males. ${ }^{49}$ Research has demonstrated that the factors that influence physical activity behavior include beliefs and attitudes towards physical activity. ${ }^{50}$ In patients with RA, factors associated with a physically active lifestyle were good physical function and high levels of exercise self-efficacy while higher levels of self-efficacy for physical activity increase the likelihood that the individual will achieve their physical activity goals. ${ }^{38,51}$ Self-efficacy is defined as a person's judgements of his/her capability to organize and execute courses of action required to attain designated types of performances. ${ }^{52}$ Our question concerning self-reported physical capacity used in our study could be interpreted as a question concerning self-efficacy for physical capacity, although the answer alternatives are not typical for self-efficacy questions. ${ }^{52}$

There are no conclusive results on whether disease activity is associated with physical capacity in SLE. ${ }^{43-45}$ Many similar studies report low disease activity in SLE; ${ }^{46,47}$ however, disease activity fluctuates through disease process and it is possible that patients with high disease activity are underrepresented in cross-sectional studies like this one.

Studies have reported that walking capacity can be affected by, for example, excess weight, ${ }^{16}$ together with psychological factors and amount of weekly physical activity. ${ }^{17} \mathrm{~A}$ study reported that individuals with SLE who performed poorly on an exercise test (treadmill) tended to have higher BMI while the results were not conclusive. ${ }^{53}$ Although it has been reported that patients with SLE are overweight compared to general population, ${ }^{46}$ in the present study, BMI was in average underweight to normal and that might also be a reason why BMI was not an indicator of physical capacity.

To our knowledge this is the first study investigating whether HRQOL and depressive symptoms are related to self-reported physical capacity in SLE. However, it still has some limitations. Our study includes bias since it may have been affected by factors that were not included in the analyses due to the use of several self-reported questionnaires. ${ }^{54}$ In spite of such potential biases, patient reported outcome data are known to be an important source of information providing insight to patients' perception of disease and health status, guiding important treatment decisions. ${ }^{54,55}$ However, our data concerning physical activity, exercise and sitting behavior could have been measured by objective measures such as an accelerometer. Furthermore, the questionnaires/questions had different timeframes, which could also be a strength in our study as we captured physical activity both from the past week but also from the past year and the latter reflecting patients' behavior/habits. Also, there were some missing data ( $>10 \%)$ in some variables such as exercise past year, depression/anxiety scores (HADS) and EQ-5D VAS that might have influenced the results. 
In conclusion, patients with SLE who reported low physical capacity reported less physical activity and that they exercised less, had less mobility and usual activities, and more pain and depressive symptoms than those who reported high capacity. Furthermore, our results indicate that besides higher age, longer disease duration and more organ damage, lower HRQOL are indicators of low physical capacity in patients with SLE with in majority inactive/mild disease activity and no or limited organ damage. The recognition that HRQOL is associated to self-reported physical capacity places focus on the importance of understanding patients' perception of their health status. Physical state of patients should routinely be assessed during follow-up to have an idea about their current physical capacity in routine clinical practice. It is also of importance to further explore how pain and depressive symptoms are associated to self-reported physical capacity in SLE. Longitudinal prospective studies with repeated measures and different disease states are needed to find out if the factors that we found associated to self-reported physical capacity are in fact predictors.

\section{Acknowledgement}

We would like to acknowledge patients in the study, further we are grateful to Sonia Möller and Birgitta Mannerstedt Fogelfors for coordination and collection of the data and to the personnel at Karolinska University Hospital.

\section{Declaration of conflicting interests}

The authors declared no conflicts of interest with respect to the authorship and/or publication of this article.

\section{Funding}

This work was supported by the Swedish Rheumatism Association, King Gustaf V's $80^{\text {th }}$ Birthday Fund, Swedish Heart-Lung Foundation (20170257), Swedish Society for medicine and Ingegerd Johansson's Foundation (SLS-713911), The Swedish Research Council (2018-02535) and Stockholm County Council (20170038).

\section{REFERENCES}

1. de Wit M, Adebajo A. Unique role of rheumatology in establishing collaborative relationships in research.
Past, present and future of patient engagement. Ann Rheum Dis 2019;78:293-6.

2. Fasano S, Margiotta DP, Navarini L, Pierro L, Pantano I, Riccardi A, et al. Primary prevention of cardiovascular disease in patients with systemic lupus erythematosus: case series and literature review. Lupus 2017;26:1463-72.

3. Zhu TY, Tam LS, Lee VW, Lee KK, Li EK. Relationship between flare and health-related quality of life in patients with systemic lupus erythematosus. J Rheumatol 2010;37:568-73.

4. Eriksson K, Svenungsson E, Karreskog H, Gunnarsson I, Gustafsson J, Möller S, et al. Physical activity in patients with systemic lupus erythematosus and matched controls. Scand J Rheumatol 2012;41:290-7.

5. Azizoddin DR, Jolly M, Arora S, Yelin E, Katz P. Patient-Reported Outcomes Predict Mortality in Lupus. Arthritis Care Res (Hoboken) 2019;71:1028-35.

6. Torbeyns T, Bailey S, Bos I, Meeusen R. Active workstations to fight sedentary behaviour. Sports Med 2014;44:1261-73.

7. Pinto AJ, Roschel $\mathrm{H}$, de Sá Pinto AL, Lima FR, Pereira RMR, Silva CA, et al. Physical inactivity and sedentary behavior: Overlooked risk factors in autoimmune rheumatic diseases? Autoimmun Rev 2017; 16:667-74.

8. Bruce IN, Urowitz MB, Gladman DD, Ibañez D, Steiner G. Risk factors for coronary heart disease in women with systemic lupus erythematosus: the Toronto Risk Factor Study. Arthritis Rheum 2003;48:3159-67.

9. O'Dwyer T, Durcan L, Wilson F. Exercise and physical activity in systemic lupus erythematosus: A systematic review with meta-analyses. Semin Arthritis Rheum 2017;47:204-15.

10. Balsamo S, Nascimento Dda C, Tibana RA, de Santana FS, da Mota LM, Dos Santos-Neto LL. The quality of life of patients with lupus erythematosus influences cardiovascular capacity in 6-minute walk test. Rev Bras Reumatol 2013;53:75-87.

11. Boström C, Dupré B, Tengvar P, Jansson E, Opava $\mathrm{CH}$, Lundberg IE. Aerobic capacity correlates to selfassessed physical function but not to overall disease activity or organ damage in women with systemic lupus erythematosus with low-to-moderate disease activity and organ damage. Lupus 2008;17:100-4.

12. Silfee V, Lemon S, Lora V, Rosal M. Sedentary Behavior and Cardiovascular Disease Risk Factors among Latino Adults. J Health Care Poor Underserved 2017;28:798-811.

13. Teixeira V, Tam LS. Novel Insights in Systemic Lupus Erythematosus and Atherosclerosis. Front Med (Lausanne) 2018;4:262.

14. Fanouriakis A, Kostopoulou M, Alunno A, Aringer M, Bajema I, Boletis JN, et al. 2019 update of the EULAR recommendations for the management of systemic lupus erythematosus. Ann Rheum Dis 2019;78:736-45.

15. Lord SR, Menz HB. Physiologic, psychologic, and health predictors of 6 -minute walk performance 
in older people. Arch Phys Med Rehabil 2002;83:907-11.

16. Satchidanand N, Fox C, Brunton K, Freudenheim J, Hassett $J$, Naughton B, et al. Exploring predictors of walking ability among community-dwelling older adults. Aging Health. 2013;9(2):189-97.

17. Yázigi F, Espanha M, Marques A, Teles J, Teixeira P. Predictors of walking capacity in obese adults with knee osteoarthritis. Acta Reumatol Port 2018;43:256-63.

18. Schoindre Y, Meune C, Dinh-Xuan AT, Avouac $\mathrm{J}$, Kahan A, Allanore Y. Lack of specificity of the 6-minute walk test as an outcome measure for patients with systemic sclerosis. J Rheumatol 2009;36:1481-5.

19. Gustafsson J, Gunnarsson I, Börjesson O, Pettersson $\mathrm{S}$, Möller S, Fei GZ, et al. Predictors of the first cardiovascular event in patients with systemic lupus erythematosus - a prospective cohort study. Arthritis Res Ther 2009;11:R186.

20. Tan EM, Cohen AS, Fries JF, Masi AT, McShane DJ, Rothfield NF, et al. The 1982 revised criteria for the classification of systemic lupus erythematosus. Arthritis Rheum 1982;25:1271-7.

21. Bae SC, Koh HK, Chang DK, Kim MH, Park JK, Kim SY. Reliability and validity of systemic lupus activity measure-revised (SLAM-R) for measuring clinical disease activity in systemic lupus erythematosus. Lupus 2001;10:405-9.

22. Gladman D, Ginzler E, Goldsmith C, Fortin P, Liang M, Urowitz $\mathrm{M}$, et al. The development and initial validation of the Systemic Lupus International Collaborating Clinics/American College of Rheumatology damage index for systemic lupus erythematosus. Arthritis Rheum 1996;39:363-9.

23. Ekblom-Bak E, Hellenius ML, Ekblom O, Engström LM, Ekblom B. Fitness and abdominal obesity are independently associated with cardiovascular risk. J Intern Med 2009;266:547-57.

24. Craig CL, Marshall AL, Sjöström M, Bauman AE, Booth ML, Ainsworth BE, et al. International physical activity questionnaire: 12-country reliability and validity. Med Sci Sports Exerc 2003;35:1381-95.

25. Ekelund U, Sepp H, Brage S, Becker W, Jakes R, Hennings $\mathrm{M}$, et al. Criterion-related validity of the last 7-day, short form of the International Physical Activity Questionnaire in Swedish adults. Public Health Nutr 2006;9:258-65.

26. Bjelland I, Dahl AA, Haug TT, Neckelmann D. The validity of the Hospital Anxiety and Depression Scale. An updated literature review. J Psychosom Res 2002;52:69-77.

27. Lisspers J, Nygren A, Söderman E. Hospital Anxiety and Depression Scale (HAD): some psychometric data for a Swedish sample. Acta Psychiatr Scand 1997;96:281-6.

28. Brooks R. EuroQol: the current state of play. Health Policy 1996;37:53-72.
29. Aggarwal R, Wilke CT, Pickard AS, Vats V, Mikolaitis R, Fogg L, et al. Psychometric properties of the EuroQol5D and Short Form-6D in patients with systemic lupus erythematosus. J Rheumatol 2009;36:1209-16.

30. Burström K, Sun S, Gerdtham UG, Henriksson M, Johannesson M, Levin LÅ, et al. Swedish experiencebased value sets for EQ-5D health states. Qual Life Res 2014;23:431-42.

31. Hosmer DW, Lemeshow S. Introduction to the logistic regression model. In: Hosmer DW, Lemeshow S, editors. Applied Logistic Regression 2nd ed. New York: John Wiley \& Sons, Inc.; 2000. p. 1-30.

32. Jensen GM, Lorish CD. Promoting patient cooperation with exercise programs: linking research, theory, and practice. Arthritis Care Res 1994;7:181-9.

33. Olesińska M, Saletra A. Quality of life in systemic lupus erythematosus and its measurement. Reumatologia 2018;56:45-54.

34. Haglund E, Bergman S, Petersson IF, Jacobsson LT, Strömbeck B, Bremander A. Differences in physical activity patterns in patients with spondylarthritis. Arthritis Care Res (Hoboken) 2012;64:1886-94.

35. Swaak AJ, van den Brink HG, Smeenk RJ, Manger K, Kalden JR, Tosi S, et al. Systemic lupus erythematosus. Disease outcome in patients with a disease duration of at least 10 years: second evaluation. Lupus 2001;10:51-8.

36. Gatto M, Zen M, Iaccarino L, Doria A. New therapeutic strategies in systemic lupus erythematosus management. Nat Rev Rheumatol 2019;15:30-48.

37. Kiani AN, Strand V, Fang H, Jaranilla J, Petri M. Predictors of self-reported health-related quality of life in systemic lupus erythematosus. Rheumatology (Oxford) 2013;52:1651-7.

38. Knittle KP, De Gucht V, Hurkmans EJ, Vlieland TP, Peeters AJ, Ronday HK, et al. Effect of selfefficacy and physical activity goal achievement on arthritis pain and quality of life in patients with rheumatoid arthritis. Arthritis Care Res (Hoboken) 2011;63:1613-9.

39. Mancuso CA, Perna M, Sargent AB, Salmon JE. Perceptions and measurements of physical activity in patients with systemic lupus erythematosus. Lupus 2011;20:231-42.

40. Yilmaz-Oner S, Oner C, Dogukan FM, Moses TF, Demir K, Tekayev N, et al. Anxiety and depression predict quality of life in Turkish patients with systemic lupus erythematosus. Clin Exp Rheumatol 2015;33:360-5

41. Zhang L, Fu T, Yin R, Zhang Q, Shen B. Prevalence of depression and anxiety in systemic lupus erythematosus: a systematic review and meta-analysis. BMC Psychiatry 2017;17:70.

42. Xie LF, Chen PL, Pan HF, Tao JH, Li XP, Zhang YJ, et al. Prevalence and correlates of suicidal ideation in SLE inpatients: Chinese experience. Rheumatol Int 2012;32:2707-14. 
43. Williams EM, Bruner L, Adkins A, Vrana C, Logan A, Kamen D, et al. I too, am America: a review of research on systemic lupus erythematosus in AfricanAmericans. Lupus Sci Med 2016;3:e000144.

44. Williams EM, Egede L, Faith T, Oates J. Effective SelfManagement Interventions for Patients With Lupus: Potential Impact of Peer Mentoring. Am J Med Sci 2017;353:580-92.

45. Somers TJ, Kurakula PC, Criscione-Schreiber L, Keefe FJ, Clowse ME. Self-efficacy and pain catastrophizing in systemic lupus erythematosus: relationship to pain, stiffness, fatigue, and psychological distress. Arthritis Care Res (Hoboken) 2012;64:1334-40.

46. Alarcón GS, McGwin G Jr, Uribe A, Friedman AW, Roseman JM, Fessler BJ, et al. Systemic lupus erythematosus in a multiethnic lupus cohort (LUMINA). XVII. Predictors of self-reported healthrelated quality of life early in the disease course. Arthritis Rheum 2004;51:465-74.

47. Gilboe IM, Kvien TK, Husby G. Disease course in systemic lupus erythematosus: changes in health status, disease activity, and organ damage after 2 years. J Rheumatol 2001;28:266-74.

48. Lox CL, Ginis KAM, Petruzzello SJ. The Psychology of Exercise: Integrating Theory and Practice: London: Taylor \& Francis; 2016.

49. Bergström G, Berglund G, Blomberg A, Brandberg $\mathrm{J}$, Engström G, Engvall $\mathrm{J}$, et al. The Swedish CArdioPulmonary BioImage Study: objectives and design. J Intern Med 2015;278:645-59.

50. Larkin L, Gallagher S, Cramp F, Brand C, Fraser A, Kennedy N. Behaviour change interventions to promote physical activity in rheumatoid arthritis: a systematic review. Rheumatol Int 2015;35:1631-40.

51. Park DJ, Kang JH, Lee KE, Bae SC, Chung WT, Choe JY, et al. Efficacy and safety of mycophenolate mofetil and tacrolimus combination therapy in patients with lupus nephritis: a nationwide multicentre study. Clin Exp Rheumatol 2019;37:89-96.

52. Bandura, A. The explanatory and predictive scope of self-efficacy theory. Journal of Social and Clinical Psychology 1986;4:359-73.

53. Hazel EM, Bernatsky S, Da Costa D, Dasgupta K, Clarke AE, Joseph L, et al. Application of a nomogram for exercise capacity in women with systemic lupus erythematosus. Clin Rheumatol 2009;28:719-22.

54. Holloway L, Humphrey L, Heron L, Pilling C, Kitchen $\mathrm{H}$, Højbjerre L, et al. Patient-reported outcome measures for systemic lupus erythematosus clinical trials: a review of content validity, face validity and psychometric performance. Health Qual Life Outcomes 2014;12:116.

55. Mathias SD, Berry P, De Vries J, Pascoe K, Colwell $\mathrm{HH}$, Chang DJ, et al. Patient experience in systemic lupus erythematosus: development of novel patientreported symptom and patient-reported impact measures. Version 2. J Patient Rep Outcomes 2017;2:11. 